\title{
0 fazer-cidade entre deslocamentos e vizinhanças: reflexões baseadas nas trajetórias urbanas de mulheres em busca de moradia no estado de São Paulo
}

Thaís Troncon Rosa ${ }^{1}$

Resumo: 0 texto apresenta reflexões de pesquisa que tomou trajetórias urbanas e suas narrativas como entradas privilegiadas para o estudo de processos de produção e apropriação de periferias urbanas. Explora a dimensão dos deslocamentos habitacionais, em seus atravessamentos de gênero, enunciando tanto os imbricamentos entre as trajetórias e as políticas urbanas, habitacionais e sociais empreendidas no Brasil nas últimas décadas, quanto algumas dinâmicas socioespaciais situadas e instituintes de outros "regimes de urbanidade" que tencionam permanentemente tais políticas e os territórios por elas produzidos, e têm na vizinhança e nas redes de relações suas principais ancoragens.

Palavras-chave: trajetórias urbanas, moradia, gênero, periferias urbanas

The make-city between displacements and neighborhoods: reflections from urban trajectories of women in search of housing in the state of São Paulo

Abstract: The text presents reflections of research that took urban trajectories and its narratives as privileged inputs for the study of urban skirts production and

1 Programa de Pós-Graduação em Arquitetura e Urbanismo - Faculdade de Arquitetura e Urbanismo Universidade Federal da Bahia (PPGAU - FAUFBA) - Salvador - Brasil - thaisrosa @yahoo.com 
appropriation processes. It explores the dimension of housing displacements, in its gender crossings, stating both the interlinkages between the trajectories and the urban, housing and social policies undertaken in Brazil in recent decades, as well as some situated socio-spatial dynamics that establishes other "regimes of urbanity", wich permanently stress such policies and the territories they produce and have their main anchorages in the neighborhood and networks of relations.

\section{Keywords: urban trajectories, housing, gender, urban skirts}

\section{Trajetórias urbanas: breves aproximações teórico-metodológicas}

"Não sou eu que mudo a história, é a história que muda todo dia". Assim, Marielen ${ }^{2}$ procurou justificar, quase sem graça, o fato de que, a cada nosso novo encontro de pesquisa, a narrativa recente de sua trajetória e de sua família se alterava: naquele momento, o envolvimento de seu filho mais velho com o mundo do crime 3 foi identificado por ela como o elemento central a operar essa transformação cotidiana nos planos, rumos e certezas de suas trajetórias urbanas e nas narrativas sobre ela. Entretanto, essa seria apenas mais uma d ntre muitas. Mobilidade, instabilidade, deslocamento: assim se trama, em grande medida, a cidade de Marielen e, nela, sua própria história. Assim, sua justificativa envergonhada, se levada a sério, pode ser o fio condutor de um emaranhado socioespacial tecido cotidianamente nas cidades, fornecendo pistas importantes dos modos como espaços, trajetórias, narrativas e experiências urbanas se constituem mútua e dinamicamente.

A pesquisa ${ }^{4}$ que movimenta este artigo propôs apreender o espaço urbano por meio das trajetórias urbanas e suas narrativas, as quais, ao invocar

2 Os nomes de todos os sujeitos da pesquisa, bem como de pessoas por eles referidas, foram alterados, na tentativa de preservar sua identidade. Ainda restam, entretanto, "dilemas éticos e políticos da etnografia 'em casa", na esteira das reflexões desenvolvidas por Fonseca (2005), tendo em vista que, na tese, não alterei os nomes de bairros, por exemplo. Aqui reside uma dimensão crucial a ser refletida no trabalho com trajetórias.

3 Ao longo do artigo, serão utilizados os seguintes critérios gráficos: termos ou expressões êmicas serão indicados em itálicos; quando se tratar da reprodução de um trecho mais longo no corpo do texto, este constará ainda entre aspas. Palavras, expressões ou citações entre aspas e não em itálicos referem-se a conceitos, categorias, fontes bibliográficas e virão acompanhadas das respectivas referências.

4 Pesquisa de doutorado desenvolvida no Programa de Pós-Graduação do Instituto de Arquitetura e Urbanismo da Universidade de São Paulo, que resultou na tese Cidades Outras: pobreza, moradia e mediações em trajetórias urbanas liminares (Rosa, 2014), desenvolvida com apoio da FAPESP. Mais recentemente, atuando como docente na Faculdade de Arquitetura da Universidade Federal da Bahia, as questões movimentadas por esta pesquisa têm sido desdobradas em outras atividades acadêmicas, como a pesquisa "Urbanidades Liminares: moradia e dinâmicas socioespaciais nas margens da cidade", contemplada em edital PROPESQ UFBA/2016. 
percursos habitacionais, ocupacionais e os deslocamentos cotidianos pela cidade, evidenciam a condensação de práticas espaciais ${ }^{5}$ de indivíduos e de suas famílias: "uma espacialização demarcada pelas temporalidades urbanas corporificadas nos espaços e territórios da cidade", conforme proposição de Telles (2006a:70). Trata-se de uma abordagem que possibilita uma mudança na escala de compreensão das já bastante debatidas relações entre pobreza e espaço urbano no Brasil, a qual se distancia de designações genéricas para se aproximar dos fluxos, dos trânsitos, das práticas e, fundamentalmente, das narrativas que produzem não configurações urbanas à parte da cidade, senão a própria cidade.

Ao articular espaços e tempos urbanos diferenciados, as abordagens centradas em "formas de mobilidade" (Grafmeyer, 1995) - fluxos migratórios, deslocamentos habitacionais, percursos ocupacionais, trânsitos cotidianos de indivíduos e suas famílias pela cidade - configuraram-se como perspectiva renovada aos pesquisadores urbanos (Telles, 2006), em especial aqueles inseridos nos debates sobre pobreza e espaço urbano, uma vez que a atenção aos trânsitos sociais e espaciais das camadas populares na cidade permitiria captar a complexidade das novas realidades urbanas, bem como os deslocamentos, processos e práticas dos sujeitos, superando muitas das limitações de noções, categorias e parâmetros estabelecidos para medir e caracterizar a segregação urbana.

De fato, como explicita Telles (2006a) a articulação entre temporalidades (tempos biográficos, geracionais, sociais e históricos), e espacialidades (marcos espaciais, referências urbanas, pontos de condensação dos deslocamentos) é constitutiva da análise de trajetórias urbanas, além dos "eventos políticos" que as atravessam (políticas urbanas, programas habitacionais, conflitos sociais, formas de ação coletiva, práticas de tutelagem). Nessa perspectiva, as dinâmicas de produção do espaço urbano se fazem ver por meio das trajetórias urbanas: do cruzamento entre elas, de seus múltiplos pontos de conexão e condensação; é possível apreender os sujeitos em jogo nas disputas pelo espaço, suas variadas posições e deslocamentos, as temporalidades urbanas coexistentes, as tramas relacionais de caráter e extensão variada ${ }^{6}$. Tal perspectiva se mostrou funda-

5 Para Certeau (2003:175), "as práticas do espaço tecem, com efeito, as condições determinantes da vida social", sendo constituídas tanto por meio do diálogo permanente entre passado, presente e imaginação de futuro, como por justaposição das dimensões qualitativamente heterogêneas de tempo e espaço.

6 Bourdieu (1998:189), em crítica à abordagem biográfica como sucessão longitudinal e coerente de acontecimentos, invoca, como contraponto, a noção de trajetória "como série de posições sucessivamente ocupadas por um mesmo agente (ou um mesmo grupo) em um espaço que é ele próprio um devir, estando sujeito a incessantes transformações". Por sua vez, algumas críticas à tal perspectiva questionam o fato de que, para o autor, o que interessaria apreender sociologicamente sobre um indivíduo seria tão somente seu 
mental à pesquisa em questão, cujo objetivo foi investigar, a título de hipótese, os nexos entre mobilidades socioespaciais, deslocamentos habitacionais, dinâmicas familiares e políticas urbanas nos processos de produção e apropriação de periferias urbanas.

A exploração etnográfica em que se configurou a pesquisa ${ }^{7}$ se deu por meio do acompanhamento de trajetórias urbanas de moradoras(es) de periferias que, nas últimas décadas, vinham transitando em busca de moradia por São Carlos, cidade de cerca de duzentos e quarenta mil habitantes no interior do estado de São Paulo-SP - Brasil, campo ampliado de pesquisa. Considerando, com Lepetit (2001), Revel (1998) e Smith (2002), a "variação da escala" como operação analítica que pressupõe um “jogo de escalas” para além de uma taxonomia do urbano, São Carlos, mais do que uma abstração escalar e categorial, é o posto de observação, no qual as relações, processos e trânsitos que emergem das trajetórias urbanas foram investigados, atentando para a relação entre o que é geral, estruturante, que reverbera em outras realidades e aquilo que é singular, específico, localizado. Ao possibilitar apreender continuidades e pontos de inflexão da produção do espaço e da experiência urbana recente, de forma situada, a investigação de trajetórias urbanas traz à tona a "cidade como plano de referência” (Telles, 2013) - não como 'cenário' ou 'reflexo' - evidenciando dimensões que colocam as questões observadas em São Carlos em diálogo com os processos em curso no mundo contemporâneo, mediante transversalidades e ressonâncias.

Apostando na radicalização de uma postura epistemológica que se pautasse efetivamente pelas trajetórias e pelas experiências urbanas das/os

deslocamento no espaço social, nas estruturas objetivas, desconsiderando aspectos subjetivos e, principalmente, o lugar das temporalidades em tal deslocamento (Kofes, 2004). Em Grafmeyer (1995), as noções de biografia e trajetória são reaproximadas, uma vez que, conforme apresenta Frúgoli (2009:61), o autor propõe a primeira "não apenas como sucessão regrada de posições ao longo da vida, mas um mapeamento das rupturas nos pertencimentos, das reorganizações nas atitudes e comportamentos e das mudanças de espaço da vida, levando, por conseguinte, a trajetórias situadas simultaneamente no tempo e no espaço - esse último, simultaneamente registro particular da vida social, mediação e unidade de observação."

7 A pesquisa de campo, de caráter qualitativo e com preocupação descritiva, privilegiou a realização de entrevistas semiestruturadas (e sua combinação com entrevistas abertas e conversas informais), além de visitas de observação reflexiva de atividades cotidianas, bem como coleta de documentação de interesse da pesquisa. Explorou-se, ainda, o acompanhamento de alguns deslocamentos (cotidianos, mas não somente) da/os interlocutora/es pela cidade. Foram, portanto, inúmeros "encontros de pesquisa" (Feltran, 2011; Bourdieu, 2008) com moradores de periferias urbanas, realizados ao longo de pouco mais de dois anos (entre 2011 e 2013). Após uma fase exploratória inicial, definiu-se, mediante uma rede de interlocutora/es, por quatro famílias cujas trajetórias de seus/suas integrantes seriam investigadas em profundidade, tendo sido realizadas entrevistas com ao menos dois/duas integrantes de cada uma delas, totalizando vinte e cinco entrevistas, além de inúmeras outras interlocuções. Uma reflexão metodológica se encontra em Rosa (2014). 
interlocutoras/es ${ }^{8}$, a sistematização e a análise dos dados coletados/produzidos tatearam a composição de cartografias espaço-temporais das mesmas, em uma concepção em que estas tratam de acompanhar deslocamentos não apenas físicos/espaciais, mas também nas próprias narrativas, nas significações e, em última instância, nas subjetividades e experiências a elas emaranhadas (Rolnik, 1989; Guattari; Rolnik, 2000; Braidotti; 2000).

Ao possibilitarem o cruzamento entre cronologias urbanas, políticas, biográficas, as trajetórias evidenciam cortes geracionais e políticos frente à produção e à experiência da cidade, permitindo cartografar, ainda, as transformações das últimas décadas no âmbito da "pobreza" e de seus territórios na cidade, nas dinâmicas socioespaciais das periferias (e as vulnerabilidades vinculadas à expansão do mundo do crime), nas políticas públicas destinadas aos "pobres" e nas formas de acesso à moradia pelas camadas populares.

Nesse sentido, a trajetória de Núbia (uma mulher negra, com 63 anos, 5 filhos e 7 netos) trouxe para o primeiro plano a questão dos deslocamentos em busca de moradia, vivenciados por ela ao longo dos últimos quarenta anos; 0 entrelaçamento à de seu filho, Jimmy (negro, 39 anos, 4 filhos), evidencia cortes geracionais e políticos frente à produção e à experiência da cidade, permitindo cartografar as transformações nas formas de acesso à moradia e nos destinos dos deslocamentos nesse período. Ao longo desse período, Núbia, por três vezes, se aproximou da possibilidade de acessar efetivamente uma moradia, mediante três momentos distintos das políticas habitacionais no país, tendo todas elas resultado em frustração e sofrimento. A temporalidade expandida dessa trajetória (e da contínua busca por uma moradia) faz emergirem as transformações das últimas décadas no âmbito da "pobreza" e de seus territórios na cidade, nas dinâmicas socioespaciais das periferias, nas políticas públicas destinadas aos

8 Dessa opção deriva, não apenas os recortes temporais e espaciais da pesquisa, mas, sobretudo, a multiplicidade de temas e questões pelos quais a mesma transita: não se tratou de elencar, a priori, um ou mais temas centrais por meio dos quais se daria toda a pesquisa e análise (como, por exemplo, o "mercado informal de habitação", o Programa Minha Casa Minha Vida, o mundo do crime); antes, das trajetórias emergiram os temas a serem tratados, que não foram abordados em si mesmos, mas por meio das questões e relações que eles permitiam iluminar, em diálogo com os objetivos da pesquisa. Nesse sentido, alinho-me a todo um debate acadêmico em curso em torno da questão das "periferias", como bem expressou Birman (2013:7): "Pesquisadores de diferentes gerações e tradições acadêmicas abordam as periferias por intermédio de análises que valorizam certa transversalidade de campos temáticos fundamentais. Não é suficiente, pois, saber que família, trabalho, religião e gênero, entre outros domínios sociais, andam juntos e se entrelaçam nas práticas sociais mais diversas. É preciso direcionar o foco e valorizar os nexos que permitem destacar certas relações de sentido que hoje se disseminam, como entre trabalho ilegal e legal, entre evangélicos e criminalidade, entre mediação feminina e políticas públicas etc. Valorizar nexos quer dizer, em muitos casos, perceber como trazem inovações na vida social". 
"pobres" e nas formas de acesso à moradia pelas camadas populares no país, evidenciado as redes, os mercados e as políticas que as constituem cotidianamente. Permite, ainda, apreender o quanto as políticas habitacionais são parte fundamental da construção (histórica) de toda uma forma de conceber a gestão das diferenças sociais na cidade, bem como os imbricamentos entre tais políticas e a movimentação de todo um mercado imobiliário informal - e, em alguns casos, também ilegal - vigente entre as camadas populares na cidade, o qual se articula a potentes mecanismos de produção de demanda para tais políticas, bem como de "gestão dos ilegalismos" (Foucault, 1987) a elas associados9.

Já as trajetórias de Beatriz e Jefferson (um jovem casal, ela branca, ele negro, com um filho pequeno à época), aproximadas às de Joana (mulher negra, 44 anos, casada, 3 filhos e 1 neta,) e seu filho adolescente, possibilitaram iluminar a relação entre a conformação do que vinha sendo considerada uma "nova pobreza" (ou, em sentido inverso, uma "nova classe média" ${ }^{10}$ e a constituição de 'novas periferias' produzidas no âmbito do Programa Minha Casa Minha Vida (PMCMV) ${ }^{11}$ no país, atentando especialmente para os longos processos de fixação nesses novos territórios e para as dinâmicas movediças implicadas nesse contexto. São duas famílias nucleares cujos deslocamentos habitacionais desembocaram, simultaneamente (em 2011), em dois empreendimentos produzidos sob duas modalidades distintas desse Programa em uma mesma região periférica da cidade ${ }^{12}$, mas que acabaram atingindo "públicos" semelhantes. O acompanhamento dessas trajetórias evidenciou continuidades e rupturas na produção de territórios e dinâmicas socioespaciais nas periferias das cidades brasileiras contemporâneas (observadas,

9 Esta trajetória foi reconstruída e desdobrada analiticamente em Rosa (2014), no capítulo intitulado "Os meandros do acesso à moradia: redes, mercados, políticas".

10 Além do estudo de Neri (2008), responsável, em grande medida, por cunhar e popularizar a expressão, destaco, em especial, as abordagens críticas que então se seguiram, como as de Pochman (2012) ou Souza (2010).

11 O Programa Minha Casa Minha Vida emergiu em meu campo como nova, absolutamente central e praticamente única forma de acesso à "casa própria”, na cidade, para as camadas populares, à época. Lançado em 2008, o Programa seria "o apogeu de uma linhagem de políticas públicas visando à redução da desigualdade social - materializada na ocupação diferencial da terra - e do déficit habitacional brasileiro". Em conjunção com outras políticas econômicas e sociais visando a superação da pobreza (como o Programa Bolsa Família; o estímulo ao crédito popular e ao mercado de consumo interno; e o aumento real do salário mínimo) o Programa foi um dos grandes responsáveis pela melhoria de indicadores socioeconômicos do país (Kopper, 2016:187). Para alguns estudos sobre o referido programa ver, por exemplo: Cardoso (2013); Ferreira (2012); Santo Amore et al (2015).

12 No caso de Beatriz e Jefferson, pela via da aquisição privada, em que se evidencia uma perspectiva de integração urbana e social pelo consumo mercantil da casa (financiada); no caso de Joana (e aqui não se trata de um projeto do casal, mas de uma aposta dela, na qual o marido vem a reboque), por meio do modelo em que mais se evidencia a articulação política pública/mercado, pela via da consecução da casa por meio de sorteio promovido por órgão público municipal. 
na pesquisa, com base na realidade de São Carlos), bem como alguns efeitos dessa 'política habitacional' nas trajetórias urbanas investigadas e nos territórios onde elas têm seus pontos de condensação, como o acirramento da territorialização da pobreza e a consolidação da diferença social inerente à consolidação do território periférico em foco, evidenciando, ainda, a produção simultânea de territórios periféricos e de linhas de clivagem internas às camadas populares que resulta das políticas urbanas e habitacionais historicamente no país. ${ }^{13}$

Ainda, a trajetória de Marielen (mulher negra, 41 anos, casada, 3 filhos) e seus dois filhos adolescentes permitiu apreender algumas dinâmicas socioespaciais e vulnerabilidades ${ }^{14}$ vinculadas à expansão do mundo do crime nas periferias (Feltran, 2011), e o lugar da casa nesse contexto. Sendo a única trajetória cuja fixação em um território se encontrava já relativamente consolidada quando do início da pesquisa (por vieses bastante específicos, se tratando de uma casa doada por uma patroa), evidencia o quanto a consecução desta casa - a experiência de ter um pé fixo -, embora seja apontada por ela como uma salvação (econômica, social, familiar, simbólica), não significou, em definitivo, a eliminação de outras dimensões de vulnerabilidade que atravessariam sua trajetória desde então, trazendo à tona uma miríade de outros trânsitos socioespaciais para além daqueles atrelados ao acesso à moradia, cujos efeitos desestabilizariam, inclusive, tal fixação, conquistada a duras penas. $\mathrm{O}$ ingresso de seu filho mais velho no mundo do crime desencadearia uma série de deslocamentos, mediações e ajustes em sua trajetória, tendo como ápice a transformação de sua casa em uma casa manjada15 e uma série de inseguranças e violências decorrentes de tal classificação. Nesse sentido, introduz outras dimensões ao contexto de velhas e novas pobrezas/periferias/dinâmicas socioespaciais perscrutadas pela pesquisa, possibilitando evidenciar alguns ordenamentos nas periferias urbanas que têm a casa como polarizador, e os modos pelos quais se produzem, se disputam, são vividos e significados pelas/os moradora/es desses territórios ${ }^{16}$.

13 Estas trajetórias constituem o cerne empírico e analítico do capítulo "Novas pobrezas, novas periferias?" em Rosa (2014).

14 As reflexões propostas na tese que movimenta este artigo ancoram-se na concepção ampliada de "vulnerabilidades socioeconômicas e civis", tal como proposta por Kowarick (2009), e na distinção entre "vulnerabilidade" e "vitimização", como proposta por Das (2011).

15 A casa manjada seria "uma casa conhecida pela polícia", que passa a fazer parte das rotas de policiamento no bairro, a ser alvo recorrente de invasões, e também a sofrer assédios mais sutis, espécies de ameaças veladas (ou nem tanto). A expressão parece sintetizar uma dimensão fundamental, referente à extensão do ato criminal ao corpo do sujeito que o realiza e de seus pares e, consequentemente, a seus espaços - 0 bairro e, em última instância, a casa.

16 No capítulo intitulado "Para além da moradia e da pobreza: vulnerabilidades territorializadas", em Rosa (2014), bem como em Rosa (2015) estas trajetórias foram narradas e analisadas em profundidade. 
Neste artigo $^{17}$, revisitei estas trajetórias buscando explorar reflexivamente, $a$ posteriori (isto é, estabelecendo um conjunto de reflexões por meio delas, baseadas nos esforços anteriores de observação, entrevistas, incursões realizados no âmbito da referida pesquisa), cruzamentos analíticos em torno de algumas dimensões de gênero que as mesmas evidenciaram, tomando como ponto de partida o fato de que os deslocamentos habitacionais e a contínua busca por moradia conectam todas as trajetórias femininas investigadas. Nesse sentido, o texto enuncia, por um lado, os imbricamentos entre tais trajetórias, alguns de seus atravessamentos de gênero e as políticas urbanas, habitacionais e sociais empreendidas no Brasil nas últimas décadas; por outro, chama atenção para algumas dinâmicas socioespaciais situadas e instituintes de outros "regimes de urbanidade" que tencionam permanentemente as normatividades inerentes a tais políticas, aos territórios e espaços urbanos por elas produzidos, e têm na vizinhança e nas redes de relações suas principais ancoragens.

\section{Deslocamentos em busca de moradia: gênero, políitcas, mediações}

À medida que a pesquisa se desenvolvia, os deslocamentos habitacionais em torno dos quais gravitam as trajetórias e experiências urbanas narradas se mostraram centrais em termos analíticos, por colocarem muitas dimensões (individuais, familiares e sociais; concretas e simbólicas; e, sobretudo, espaciais) em dinâmica e relação frente ao universo das periferias: a contínua busca por um lugar na cidade (e as vicissitudes, inseguranças e violências decorrentes), assim como sua dialética com os pontos de fixação destas trajetórias em determinadas casas e territórios orientam significativamente a relação de minhas interlocutoras com a cidade e a construção, desconstrução e reconstrução de relações com pessoas, espaços e políticas.

Faz-se importante, aqui, destacar que, embora a dimensão de gênero não tenha sido um recorte apriorístico da pesquisa, foi no curso de seu desenvolvimento (ou seja, uma consequência do seu próprio campo), e por meio das próprias questões que as trajetórias traziam à tona, que tal dimensão foi se fazendo presente, até o ponto em que todas as interlocutoras principais foram mulheres: de um lado, constatou-se a recorrência de deslocamentos habitacionais e trajetórias

17 O presente artigo é uma versão adaptada da comunicação apresentada no Seminario Internacional “Trayectorias, Trabajo y Género", organizado pelo Laboratorio Misto Internacional (LMI) - Social activities, gender, markets and mobilities from below (Latin America) e o Programa Envejecimiento y Sociedad da Facultad Latinoamericana de Ciencias Sociales (FLACSO Argentina), em 2018, em Buenos Aires. Tendo em vista a temática do evento, tratou-se de um exercício preliminar que, ainda que revisite a pesquisa de campo e as trajetórias etnografadas/cartografadas, caminhou no sentido de uma reflexão teórico-analítica. Nesse sentido, para a densidade do campo, remeto uma vez mais à Rosa (2014). 
de busca por moradia entre estas mulheres das camadas populares; de outro, a reafirmação, por meio das narrativas, da centralidade da moradia nesses atravessamentos de gênero, ancorados em arranjos matrifocais que perpassam relações familiares ampliadas, conjugais, filiais ou mesmo de vizinhança.

Para além das muitas camadas de vulnerabilidades recorrentes nessas trajetórias de mulheres em "situação periférica" (Almeida et al, 2009) - migrações interurbanas, violências domésticas na infância e adolescência, o trabalho precoce como empregadas domésticas e relações de obrigação para com patroas, a gravidez na adolescência, o abandono ou expulsão da casa da família, processos de subordinação e libertação da dependência masculina, a intermitência laborial em função de gravidezes e filhos, para citar algumas ${ }^{18}$-, os deslocamentos habitacionais e a contínua busca por moradia são, de fato, aquelas que aproximam todas as trajetórias femininas investigadas (e não apenas as quatro desdobradas em profundidade na tese): estão diretamente relacionadas aos diversos arranjos entre mulheres, sobretudo quando mães solteiras, para construir as mediações necessárias para a persistência na vida na cidade, dentre os quais destacam-se a coabitação feminina, o intercâmbio de tarefas domésticas, a circulação de crianças, ou as redes de informações, para citar algumas, e que vinculam sobremaneira as possibilidades de algum tipo de fixação (em termos de moradia) e o enfrentamento das incidências gestionárias do estado (mas também do mundo do crime) sobre suas vidas e, principalmente, de seus filhos.

Assim, a experiência urbana de minhas interlocutoras está absolutamente entramada a essa dinâmica de deslocamentos habitacionais sucessivos, migrações intraurbanas cuja regularidade demarca uma certa condição de "nomadismo" (Lindón, 2007; Rizek, 2014), que parece ser parte estruturante dos processos simultâneos de produção de subjetividades e territorialidades para os quais a pesquisa atentou, e configura-se mesmo como aspecto banalizado das condições de habitação e inserção urbana das camadas populares.

Núbia, por exemplo, se valia recorrentemente da expressão caçar rumo, que acaba por sintetizar não apenas sua condição durante grande parte de sua trajetória, mas também a de diversas outras interlocutoras, associando-se a constatação de "ter que se virar sozinha", em tudo distante tanto dos direitos como das tutelagens sociais. Evocada por ela em relação ao contexto de ruptura completa com os vínculos

18 Ainda nesse sentido, tais trajetórias evidenciam o que a literatura denominou "feminização da pobreza", bem como os caminhos e descaminhos da incorporação de um corte de gênero nas políticas públicas (como as políticas sociais, ou mesmo as habitacionais): destaco, nesse sentido, o fato de três de minhas quatro interlocutoras principais terem recebido o Bolsa Família durante intervalos de tempo em que estiveram sem um companheiro contribuindo no sustento da família. 
familiares (pais, irmãos etc) e construção de novas redes de relações, em grande medida mediadas por seu então novo papel de mãe, a ideia de caçar rumo aponta para uma introjeção da dimensão do acesso a moradia como dever privado, algo que dependeria exclusivamente dela, individualmente e/ou articulada a suas redes.

Essa talvez seja a principal dimensão a estruturar uma experiência urbana comum dentre minhas interlocutoras, moradoras das periferias de São Carlos: aquela de, em algum momento da vida (ou em toda ela), "não ter lugar", "não ter para onde ir", "morar de favor", "ter de caçar rumo" em que se vislumbra uma forte marcação de gênero - da qual a figura da mãe é emblemática, por ocupar lugar decisivo como definidora dos rumos das trajetórias familiares e das concepções de cidade que constroem e nas quais se pautam. Trajetórias marcadas por sequências de rupturas e recomeços, desenraizamentos sucessivos vividos muitas vezes como traumas, em que a ausência de moradia se vincula à presença do estado como ator de violências múltiplas no campo do urbano, apontando para a coexistência de mecanismos históricos de gestão das diferenças sociais na cidade e processos contemporâneos de gestão diferencial de territórios. ${ }^{19}$

Suas trajetórias permitiram entrever uma ampla envergadura de dimensões relativas à problemática do acesso à moradia ao longo dos últimos quarenta anos, na qual os deslocamentos entre cortiços, casas de cômodos, coabitações, barracos, aluguéis informais e seus atravessamentos por dimensões de violência estatal, como as remoções forçadas ou mecanismos de exclusão seletiva dos programas habitacionais apontam para os imbricamentos entre tais trajetórias e as políticas habitacionais no Brasil, em especial a desconexão entre tais políticas e a realidade urbana e social das camadas populares, bem como os efeitos da mudança de escala operada na última década (por meio do Programa Minha Casa, Minha Vida - PMCMV) e seus efeitos sobre toda uma geração.

E, se tal dimensão 'nômade' se faz presente nestas trajetórias como condição de vida, mostra-se também elemento estruturante dos processos de produção da cidade: levando em consideração as trajetórias se evidencia o quanto a expansão urbana se produz, em grande medida, para e pelas camadas populares, em um contínuo "fazer cidade em suas margens" (Agier, 2011). À experiência

19 Nunca é demais destacar que, muito além de um 'elogio ao nomadismo' (presente em diversos estudos que têm seu foco na mobilidade e nos deslocamentos contemporâneos), os deslocamentos de que falam as trajetórias aqui tratadas têm uma dimensão bastante trágica e falam ora da ausência de lugar na cidade, ora de uma espécie de detenção em lugares (limiares) indefinidos e incertos (aproximando - com as devidas mediações - a concepção de desenraizamento às de "desplazamientos" ou à de "destierro", que, apesar de referirem-se primordialmente a refugiados de conflitos armados extremos, também estão presentes na literatura latino-americana acerca da pobreza e das periferias urbanas, cf. pe. Lindón, 2007), apontando para a violência imanente aos processos de urbanização e às dinâmicas relativas ao acesso à moradia. 
comum dos deslocamentos habitacionais se soma, portanto, a do viver em bairros por fazer, do morar em casas inacabadas, do contínuo refazer de relações e espaços. Disso decorrem concepções de casa, vizinhança, bairro, cidade, vividos como processo (sempre inacabado), entendidos como constructos dinâmicos, e não como estruturas fixas no tempo, pautados sempre por um horizonte de melhoria progressiva, espécie de "imaginação do futuro" (Cavalcanti, 2007).

E esse é um dos pontos de vista pelo qual se deve compreender a centralidade da casa (como presença ou ausência) nessas trajetórias: articulada às experiências anteriores de deslocamentos - e de, por vezes, "não ter pra onde ir" -, a "casa própria" se configura não somente como este horizonte de melhoria, mas como possível ponto de repouso (ainda que não, necessariamente, de fixação), como desejo de permanência frente a esse nomadismo continuado. A construção dos sentidos de "ter uma casa" se faz em íntima relação com a experiência vivida dos múltiplos deslocamentos, das vicissitudes e sofrimentos decorrentes de "não ter casa". De modo complementar, as vivências anteriores da casa como lócus de violências (sobretudo no caso das mulheres) dão lugar ao ideal da casa como abrigo; as inseguranças e incertezas nas demais esferas da vida fazem depositar na casa (própria) a dimensão mais ontológica de segurança - ainda que tais dimensões ideais (dentre outras) estejam em contínua tensão com a realidade cotidiana, com outras esferas de vulnerabilidade que a atravessam, mesmo quando o acesso à moradia se concretiza de alguma maneira.

A presença ou ausência da casa relaciona-se diretamente com inúmeros atravessamentos, nas trajetórias, em termos de relações com o estado: para além da aproximação (ou não) às políticas habitacionais. Dessa forma, as trajetórias de minhas interlocutoras são atravessadas, em diversos momentos, por relações com assistentes sociais, juízes, delegados e policiais. Atravessamentos em grande medida pautados pela própria dimensão de gênero (nos quais ter ou não moradia é algo decisivo), quase sempre vinculados ao lugar de "mãe" ocupado por essas mulheres, em dinâmicas por tentar garantir a guarda dos filhos, ou, em sentido mais extremo, preservar sua vida, nos quais poder mobilizar a existência de uma casa fixa se sobrepunha, inclusive, à mobilização da identidade de trabalhadora por essas mulheres ${ }^{20}$.

20 De fato, nas trajetórias de Núbia e Marielen (e em diversas outras evocadas por elas, ou acompanhadas por mim de maneira informal), em mais de uma ocasião a ausência de moradia (ou, sobretudo, o argumento de autoridade sobre a ausência de "moradia adequada") quase as impediriam de criar os próprios filhos. Nesse sentido, também uma passagem da trajetória de um ex-interno da Febem reconstituída por Mallart (2011:47) chama a atenção para essa questão, apontando para uma experiência comum, em que gênero, raça e classe se articulam em termos da impossibilidade de vida digna para as mães solteiras e pobres (em sua maioria negras) na cidade, em que a questão da moradia desempenha papel fundamental. 
É dessa perspectiva que a busca por moradia emerge nas trajetórias como foco principal, entre minhas interlocutoras, dentre as táticas de persistência na vida, condição que antecede até mesmo a busca por trabalho, porque considerada primordial para poder, inclusive, trabalhar. Núbia, aos dezoito anos, somente consegue deixar a casa do pai - lócus de inúmeras violências sofridas por ela - ao conseguir um trabalho como doméstica fora da cidade natal, porque este tinha como garantia a moradia na "casa da patroa". Desde então, nos mais de quarenta anos de "praga de cigano", como ela se refere à sua trajetória de deslocamentos habitacionais na cidade de São Carlos, entre um trabalho mais perene como doméstica na casa de uma única família, e os diversos momentos desempregada ou atuando como catadora de frango ou de materiais recicláveis, em nenhum momento em suas narrativas a busca por trabalho foi evocada como algo que direcionou os rumos de sua trajetória urbana, que se pautava sobretudo nas possibilidades de arcar com os custos de uma moradia, transitar facilmente pela cidade, ter acesso às instituições e redes de relações que favorecessem o cuidado com as crianças.

Mesmo no caso de Joana, cujo trabalho como costureira, na oficina situada na casa de sua mãe (onde ela também morava), se mostraria completamente sacrificado em função do deslocamento para a "casa própria" conseguida "do outro lado da cidade" via PMCMV, o investimento em garantir uma casa fixa se colocava acima da própria manutenção do trabalho, o qual ela considerava que conseguiria reestabelecer, inclusive, por meio de sua nova moradia, invocando as inúmeras experiências de intermitência laborial ao longo da vida: "trabalho a gente dá um jeito, agora casa... é mais difícil, né?” De fato, diante de um pé fixo, se faz possível tecer redes de relações que viabilizam não apenas a própria consecução de trabalhos, mas também os apoios nos cuidados com as crianças para que as mulheres possam trabalhar. Além disso, "não ter casa" representa, entre minhas interlocutoras, uma das principais marcas associadas a uma ideia de pobreza, conforme apontam também Guedes e Lima (2006:133): "O acesso a uma casa - que representa sua inclusão em uma família - pode representar a diferença entre a possibilidade de se manter nos segmentos mais estabilizados da classe trabalhadora ou de se transformar em um morador de rua, naquele 'trabalhador que não deu certo'(...)".

$\mathrm{Na}$ tensão entre as incidências gestionárias do estado sobre suas vidas (quase sempre vinculadas aos enquadramentos da maternidade ${ }^{21} \mathrm{e}$, em menor grau, do trabalho) e as violências delas decorrentes, em associação com uma

21 Destaco novamente, nesse sentido, a recorrência, nas trajetórias, da perversa relação entre ter ou não ter moradia e poder ou não assumir o cuidado dos filhos. 
dimensão de vulnerabilidade cada vez mais multifacetada (e cuja aproximação de diversas formas ao "mundo do crime" tende a acentuar), a fixação em uma moradia permite ampliar as possibilidades de manejar, responder ou desviar de tais incidências e violências, mobilizando configurações familiares e a composição de diversos outros arranjos cotidianos, dentre os quais se destaca a árdua construção da vizinhança, quase sempre numa articulação entre mulheres.

\section{Da busca por moradia à vizinhança como luta: ancoragens e tessituras possíveis em meio aos trânsitos}

Como contraponto às dinâmicas cambiantes em diversos aspectos da vida (trabalho, renda, arranjos familiares, vínculos sociais etc.), a perspectiva de fixação em uma casa e um território é, portanto, um dos principais horizontes das trajetórias, ao qual se articula a dimensão fundamental de construção de redes de relações situadas, de uma territorialidade propriamente $\operatorname{dita}^{22}$ - a vizinhança.

A investigação das trajetórias urbanas evidenciou a construção de um sentido bastante elástico de família - e, consequentemente, de $\operatorname{casa}^{23}$ - os quais se mostraram intrinsecamente ligados ao sentido de vizinhança, cujas experiências de construção e reconstrução são mobilizadas continuamente nas narrativas de minhas interlocutoras, e orientam, em grande medida, toda sua experiência urbana e suas dinâmicas habitacionais. A vizinhança expressa, mesmo, uma espécie de síntese entre família, casa e território, a qual vincula-se à possibilidade de construção de redes de relações no tempo e no espaço e configura uma experiência urbana traduzida nas categorias êmicas ser conhecido e ter conhecimento.

Tais categorias (mobilizadas não apenas pelas mulheres, mas sobretudo por elas, em especial nas batalhas cotidianas pela segurança dos filhos, seja perante o tráfico ou a polícia) referem-se, simultaneamente, às pessoas e ao espaço, de forma imbricada: ser conhecido significaria estar imerso em redes de relações sociais que implicam necessariamente algum tipo de vinculação ao território, seja pelo fato de ser nascido e criado ou, ao menos, morador antigo em um determinado lugar ("aqui todo mundo me conhece"; "aqui, onde eu vou tenho um conhecido"; "aqui todo mundo sabe minha índole"), opondo-se àqueles considerados estranhos; de forma complementar, ter conhecimento expressa o outro

22 Lindón (2005:4) irá destacar a importância, para as camadas populares, de "ter alguma certeza territorializada”.

Para uma reflexão mais aprofundada sobre essa plasticidade da família, da casa e da vizinhança entre as camadas populares, remeto à tese (Rosa, 2014), e a alguns trabalhos que me foram esclarecedores nesse sentido: Marcelin (1999), Guedes (1998, 2008), Guedes e Lima (2006), Duarte e Gomes (2008). 
lado da balança, reunindo tanto os contatos e boas relações cultivadas no tempo e no espaço, quanto o domínio físico e simbólico sobre um território ("eu conheço esse lugar como a palma da minha mão"; "conheço cada buraquinho aqui"; "aqui eu sei quem é quem"; "aqui eu sei onde encontrar ajuda").

Essas categorias, que ajudam a delinear a noção de vizinhança - delimitação simbólica de um território sobre o qual se tem conhecimento socioespacial e no qual se é reconhecido - são apreendidas a um só tempo como fonte de pertencimento e de segurança, sintetizadas na distinção êmica entre lugar tranquilo e lugar pesado: a construção da vizinhança remete, entre outros aspectos, a práticas cotidianas e elaborações simbólicas que permitem vivenciar estes territórios periféricos como "lugares seguros"24, mesmo em casos de convívio cotidiano com o crime, o tráfico e a violência policial.

Na construção dessa ideia de vizinhança, uma terceira dimensão se expressa na categoria movimento, que possui dupla acepção, associada respectivamente às noções de lugar tranquilo e lugar pesado. De um lado, há o movimento referente ao cotidiano corriqueiro do bairro, que minhas interlocutoras tanto valorizam: são as pessoas nas ruas, a conversa entre vizinhos, a troca de informações entre colegas, os encontros rotineiros. A essa ideia positiva de movimento ainda se associa a possibilidade de circular pelo bairro para suprir demandas rotineiras por serviços e também, nesses deslocamentos cotidianos, estabelecer essas trocas sociais que animam a vida local. De outro, refere-se às dinâmicas do "tráfico de drogas" e a uma presença significativa do mundo do crime em um determinado território, do qual a faceta mais visível seria a constante presença de meninos envolvidos na rua, nas esquinas, a circular "dia e noite". Entre minhas interlocutoras, tal movimento foi, em geral, valorado negativamente, sobretudo pelo fato de que, onde este é mais intenso, a presença policial também seria.

Tais categorias êmicas, brevemente apresentadas, reiteram os já mencionados imbricamentos entre espaço e redes de relações inerentes à ideia de vizinhança, e sustentam a dimensão, frequentemente apreendida em campo, de que as redes de relações situadas se configurariam como o principal "bem" de minhas interlocutoras, em alguns casos ainda mais valorizado que a casa (embora diretamente vinculado à ela). Trata-se mesmo de uma possível distinção geracional: se a dimensão processual de autoconstrução da casa, a que se associava

24 Para desdobramentos nesse sentido, vejam-se as reflexões de Segura (2009); Rocha (2009), Machado da Silva e Leite (2007). Veja-se também o que aponta Guedes (2008:8): "as relações de vizinhança expressam-se também em avaliações discursivas frequentes conectando a tranquilidade do lugar e a vizinhança”. 
a ideia uma luta familiar vinculada diretamente às dinâmicas do mundo do trabalho, marcou historicamente a produção das periferias brasileiras e toda uma economia moral em torno da "casa própria" ${ }^{25}$, mais recentemente, em um contexto em que a expansão dos mercados formal e informal de compra e aluguel se associa à retração da autoconstrução como forma principal de acesso à moradia, é a vizinhança que parece congregar tal dimensão de luta (ancorada menos em dimensões materiais do que simbólicas), em razão dos árduos processos de construção, reconstrução e consolidação de redes de relações locais vinculados aos múltiplos deslocamentos habitacionais.

Mas, se por um lado a perspectiva de fixação em uma casa e um território é um dos principais horizontes das trajetórias, por outro - e, paradoxalmente, tendo em vista o contexto de produção habitacional massiva pelo PMCMV na última década - a "casa própria" parece já não configurar, necessariamente, um horizonte de estabilidade das camadas populares (como ideal, talvez; mas na prática, não), não representa o ponto final de condensação das trajetórias habitacionais. Mesmo no contexto recente, em que as políticas sociais e habitacionais brasileiras se direcionaram, cada vez mais, a territorializar a pobreza, amplificando e espraiando em cidades ao longo do país a produção de novos territórios periféricos - a persistência, a renovação ou o acirramento de certas condições e vulnerabilidades impulsionam outros deslocamentos, pondo em xeque a própria questão da fixação.

De fato, o "nomadismo" evidencia-se como força estruturante que vai além, inclusive, do atendimento pelas políticas habitacionais, em uma dinâmica que não necessariamente se interrompe pela conquista da "casa própria". Os processos de fixação nas novas casas e nos novos bairros são tensionados, o tempo todo, pelas constantes mudanças e instabilidades em todos os outros aspectos da vida, como arranjos cotidianos envolvendo situações de emprego e desemprego, trânsitos religiosos, circulação dos filhos entre casas e bairros, para citar alguns, sendo muitas delas também decorrentes da mudança de bairro e de casa. As mulheres, sobretudo em sua condição de mãe, têm papel determinante não apenas nos processos de conquista da casa e de mudança, mas também nos rumos do processo de fixação nos novos territórios, que envolvem novas relações entre casa, trabalho, cuidados com os filhos e os deslocamentos cotidianos na cidade.

São diversos os vetores observados a incidir sobre a continuidade dos deslocamentos habitacionais mesmo após a consecução de uma casa: para além das

25 Para duas referências contemporâneas deste debate, dentre outras, ver: $\operatorname{Kopper}(2013,2014)$ e Cavalcanti (2007, 2009). 
dimensões financeiras aí implicadas (dificuldades em arcar com os custos das novas moradias e da infraestrutura urbana formalizada, aumento nos gastos com transporte em função da localização da nova moradia, distância em relação a possibilidades de obtenção de trabalho e renda, para citar alguns exemplos), muitos destes vetores relacionam-se, em alguma medida, com as próprias concepções de vizinhança aqui esboçadas. Dentre eles, três merecem destaque por terem se mostrado, em maior ou menor grau, também dimensões constituintes da mencionada experiência urbana comum, aspectos estruturantes das trajetórias em foco.

O primeiro trata das já mencionadas dinâmicas familiares cambiantes e seus rearranjos constantes: os movimentos de constituição, destituição e restituição das famílias, assim como o caráter plástico das mesmas, que permite que se conciliem modelos nucleares e conjugais com modelos de família extensa, imersos nas relações de vizinhança ou parentesco por afinidade, acabam sendo responsáveis por pautar, em grande medida, direções, escalas e intensidades dos deslocamentos, bem como por tensionar significativamente os processos de fixação nos novos territórios e nas novas casas.

O segundo refere-se ao atravessamento das trajetórias por dinâmicas inerentes à "expansão do mundo do crime nas periferias" (Feltran, 2011): sua maior ou menor presença, concentração e capilaridade em um determinado território são fatores a motivar deslocamentos mais recentes (voluntários e involuntários), seja pela intenção de fugir dessas dinâmicas, muitas vezes sob a perspectiva de "poder criar um filho de forma decente, com segurança"; de desvincular-se dessa proximidade, corporal inclusive; de tentar escapar ao estigma e à suspeição dirigidos a determinados territórios; de tirar a família dos limites imediatos de ação e domínio do crime; ou mesmo de tentar eliminar os efeitos de tais dinâmicas de dentro da própria casa, entre outros fatores, a depender do envolvimento, direto ou não, com tal universo. Trata-se de uma dimensão mais ampla de vulnerabilidade que, inclusive, desestabiliza famílias relativamente enraizadas em um certo território.

O terceiro, embora presente em outros contextos, ganha força significativa após a implementação do PMCMV e a expansão do mercado habitacional às camadas populares, e articula-se diretamente aos outros dois vetores mencionados: trata-se dos projetos individuais e familiares de mobilidade socioespacial em que a mudança de casa é apreendida ora como espécie de 'conversão', visando a distanciar-se das marcas da pobreza, dos estigmas territorializados, de uma "vizinhança ruim"; ora como perspectiva de negócio futuro, nos casos em que a mudança envolve planos de aquisição e subsequente venda ou aluguel da "casa própria" como uma etapa planejada deste projeto, mirando o deslocamento subsequente rumo a um território e uma vizinhança "mais valorizados". 
Há, portanto, uma relação de tensão e complementaridade entre o lugar da casa nas trajetórias urbanas e os múltiplos trânsitos (territoriais, sociais) que as configuram, a qual parece ser central nessas experiências urbanas "periféricas": de um lado, as dimensões de territorialização e fixação presentes na concepção mesma de moradia, mas, sobretudo, historicamente, nas políticas habitacionais (e sociais) no país, extremamente amplificadas no contexto da produção massiva implementada pelo PMCMV; de outro, o caráter dinâmico e transumante inerente às trajetórias investigadas, que tem como cerne arranjos familiares e redes de relações cambiantes que não se pautam unicamente pela estabilidade e rigidez dos vínculos, mas, ao contrário, por sua plasticidade (aqui incluídas também a plasticidade das noções de casa e vizinhança), e são atravessados por múltiplas camadas de vulnerabilidades e violências. Tal complexa relação é sistematicamente ignorada pelas políticas públicas brasileiras, que seguem pautando-se por uma imagem fixa de família, de casa (e mesmo de cidade), ignorando tal plasticidade (e a diversidade) presente nas experiências de família, casa e, sobretudo, vizinhança nas camadas populares, associadas que estão às experiências de deslocamentos, e que são constituintes do que denomino 'cidades outras', invocando a alteridade para o centro dos debates sobre políticas urbanas e habitacionais no Brasil.

Ao perscrutar que cidades se configuram do ponto de vista de tais deslocamentos habitacionais e seus pontos de fixação (casas, vizinhanças, bairros), deparei-me com uma dimensão indelével dessas trajetórias, qual seja, o fato de conformarem experiências urbanas absolutamente mediadas pelas redes de relações estabelecidas no tempo e no espaço, por trânsitos e deslocamentos no espaço físico e no espaço social, entre mundos sociais e territorialidades (Graffmeyer, 1995).

Assim, mesmo em meio a uma inegável intensificação da territorialização da pobreza, a cidade que emerge da pesquisa empírica se apresenta como campo de trânsitos e mediações, em que se articulam temporalidades, espacialidades e universos sociais distintos (mundo do crime, religião, trabalho, família, políticas públicas, instituições etc.). Os trânsitos compulsórios ou voluntários (e aqui me refiro aos deslocamentos não apenas físicos, já que envolvem também dimensões simbólicas) empreendidos por estas mulheres, moradoras das periferias, parecem se configurar como um elemento fundamental para a reflexão em termos da produção das cidades contemporâneas, e se mostraram aspectos importantes para uma aproximação à complexidade socioespacial das periferias urbanas investigadas. 
As interlocutoras da pesquisa são operadoras de conexões de mundos, "figuras de fronteira" (Foote-Whyte, 2005): suas identidades e ações são situacionais, compõem-se de uma superposição de estados situados. Os dispositivos acionados, as instâncias mobilizadas, os espaços atravessados evocam relações e mediações que configuram simultaneamente territórios e experiências urbanas pautadas sob ordenações e normativas múltiplas (muito além das dicotomias formal/informal; legal/ilegal), em movimento, muitas vezes em disputa, e quase sempre coexistentes (quiçá superpostas), acionadas conforme dinâmicas cotidianas que evidenciam espécies de 'saberes de deslocamentos': rituais cotidianos de atualização dos conflitos, das violências, das rupturas, dos descaminhos como modos de reconstruir cotidianamente a própria vida na cidade, bem como os espaços onde ela transcorre.

Os lugares de moradia - e as vizinhanças aí construídas - são fundamentais nesse sentido, e influenciam sobremaneira as extensões, dimensões e capilaridades de tais trânsitos e dos saberes deles decorrentes, e vice-versa. Vistos no tempo, trânsitos e saberes mostram-se mesmo indissociáveis das motivações que poderão produzir novos deslocamentos pela cidade. Paradoxalmente, a casa - ponto de fixação - é também um polo irradiador dessas tramas e mediações de que se faz a cidade, a começar pela vizinhança. É baseado no lugar da casa (ou das várias casas pelas quais já passaram) que se tecem redes de conhecimento e relações que constroem e interconectam vizinhanças, bairros, territórios e as "cidades outras" que aí se tramam: cidades feitas de deslocamentos, desenraizamentos, ajustes e ausências, mas também de relações, mediações, projetos e afetos, cuja multiplicidade de dimensões históricas, concepções em ato ou devires possíveis somente se dão a apreender por meio das trajetórias e narrativas dos sujeitos.

Apreendidas deste modo, as motivações dos deslocamentos habitacionais e de seus momentos de fixação se mostraram muito mais complexas do que o imediatismo das explicações socioeconômicas ou de categorias como "segregação" ou "exclusão" podem fazer parecer e mostraram-se fundamentais para se repensar os sentidos de cidade, bairro, casa e as políticas que a eles se entrelaçam. A despeito dos bloqueios e constrangimentos, as "cidades outras" que emergem das trajetórias não se pautam exclusivamente pela "lógica da necessidade", evidenciando um campo de experiência e significação da cidade (a um só tempo comum e diverso). Como atesta Lindón (2005), os habitantes dessas sucessivas "novas periferias" não seguem passivamente as pautas de especuladores, mercados ou políticas: "Estes atores também produzem valorações, tomam decisões, perseguem objetivos, (...) são ativos neste processo que não se reduz a estender os limites da cidade, mas que implica construí-lo em um 'lugar"'. 
Mesmo considerando-se que, a despeito de melhorias nas condições econômicas das camadas populares ao longo das primeiras décadas dos anos 2000 no Brasil (que fizeram a pobreza ainda mais heterogênea), manteve-se a experiência da cidade sob o signo da vulnerabilidade ${ }^{26}$, evidenciando dimensões de "produção da vida nua nas circunstâncias concretas de vida e trabalho dos que habitam e transitam por esses territórios" (Telles, 2013:361), levar a sério as trajetórias e suas narrativas implica constatar que também se desvelam horizontes de projetos - por meio de determinados "campos de possibilidades" (Velho, 1994), é verdade -, que podem reconfigurar experiências urbanas atravessadas por variadas formas de violência e vulnerabilidade.

E é dessa perspectiva que propus aqui, apreender a noção de vizinhança, tão cara às minhas interlocutoras: na inegável dimensão de agência inerente à sua construção processual, como momentos de criação de territorialidades (mesmo que transitórias) entre deslocamentos; nas disputas cotidianas por conformar dimensões outras de produção do espaço urbano por meio de outros significados de casa e família, e mesmo perante os enfrentamentos cotidianos da vulnerabilidade. Mas, sobretudo, na sempre renovada insistência em dotar de urbanidade, em "tornar cidade" esses sempre novos territórios produzidos de forma a confinar a pobreza. A investigação das trajetórias urbanas faz emergir a vizinhança como espaço-tempo relacional, apontando para a existência de outros "regimes de urbanidade" (Agier, 2011) que tensionam permanentemente as normatividades inerentes às políticas urbanas, habitacionais e sociais. Construídos com base nas experiências dos deslocamentos habitacionais, acabam por tensionar, também, as dimensões gestionárias e territorializadoras da pobreza sob as quais se delinearam boa parte de tais políticas no Brasil, em um "fazer-cidade" construído, cotidianamente, como luta.

\section{Referências}

AGIER, Michel. Antropologia da cidade: lugares, situações, movimentos. São Paulo, Terceiro Nome, 2011.

ALMEIDA, Ronaldo; D’ANDREA, Tiaraju; DE LUCCA, Daniel. Situações periféricas: etnografia comparada de pobrezas urbanas. Novos Estudos Cebrap, São Paulo, 2009. BIRMAN, Patricia. Apresentação. CUNHA, Neiva Vieira da; FELTRAN, Gabriel de Santis. (orgs). Sobre periferias: novos conflitos no Brasil contemporâneo. Rio de Janeiro, Faperj/Lamparina, 2013.

BOURDIEU, Pierre (org.). A miséria do mundo. Petrópolis, Vozes, 2008.

26 Acentuadas brutalmente nos últimos anos, após a conclusão desta pesquisa, sobretudo a partir de 2016, e com maior intensidade na entre 2018 e 2019. 
BOURDIEU, Pierre. A ilusão biográfica. AMADO, Janaina; FERREIRA, Marieta de Morais. (orgs.). Usos e Abusos da História Oral. Rio de Janeiro, Editora FGV, 1998.

BRAIDOTTI, Rosi. Sujetos nómades. Buenos Aires, Paidós, 2000.

CAVALCANTI, Mariana. Of shacks, houses, and fortresses: An ethnography of favela consolidation in Rio de Janeiro. Tese (Doutorado). Departamento de Antropologia, University of Chicago, 2007.

. Do Barraco à Casa: tempo, espaço e valor(es) em uma favela carioca. Revista Brasileira de Ciências Sociais, 2009.

CARDOSO, Adauto (Org.). O Programa Minha Casa Minha Vida e seus efeitos territoriais. Rio de Janeiro, Letra Capital, 2013.

CERTEAU, Michel de. A invenção do cotidiano: artes de fazer. Petrópolis, Vozes, 2003.

DAS, Veena. O ato de testemunhar: violência, gênero e subjetividade. Cadernos Pagu, n. 37, 2011, pp. 9-41.

DUARTE, Luiz Fernando Dias; GOMES, Edlaine de Campos. Três famílias: identidades e trajetórias transgeracionais nas classes populares. Rio de Janeiro, Editora FGV, 2008. FELTRAN, Gabriel de Santis. Fronteiras de tensão: política e violência nas periferias de São Paulo. São Paulo, Editora Unesp/CEM/CEBRAP, 2011.

FERREIRA, João Sette Whitaker (coord). Produzir casas ou construir cidades? Desafios para um novo Brasil urbano. Parâmetros de qualidade para a implementação de projetos habitacionais e urbanos. São Paulo: LABHAB; FUPAM, 2012.

FONSECA, Claudia. O anonimato e o texto antropológico. Dilemas éticos e políticos da etnografia 'em casa'. Anais da VI RAM, Mesa Redonda Trayectorias y diversidade: las estrategias en investigación etnográfica, Montevideo, 2005.

FOOTE-WHYTE, Willian. Sociedade de Esquina. Rio de Janeiro, Zahar, 2005.

FOUCAULT, Michel. Vigiar e punir. Petrópolis, Vozes, 1987.

FRÚGOLI Jr., Heitor. A cidade no diálogo entre disciplinas. In: FORTUNA, Carlos; LEITE, Rogério Proença. (Org.). Plural de cidade: novos léxicos urbanos. Coimbra, Almedina, 2009, pp. 53-67.

GRAFMEYER, Yves. Sociologia urbana. Mira-Sintra: Publicações Europa-América, 1995. GUATTARI, Felix; ROLNIK, Sueli. Micropolítica - cartografias do desejo. Petrópolis, Editora Vozes, 2000.

GUEDES, Simoni Lahud. Redes sociais urbanas: casa, família e vizinhança. Anais $26^{a}$ Reunião Brasileira de Antropologia, Porto Seguro, 2008.

. Redes de parentesco e consideração entre trabalhadores urbanos: tecendo relações a partir de quintais. Caderno CRH, Salvador, n. 29, 1998.

; LIMA, Michelle da Silva. "Casa, família nuclear e redes sociais em bairros de trabalhadores". BARROS, Myriam Lins. (org.). Família e gerações. Rio de Janeiro, FGV Editora, 2006. 
KOFES, Suely. Os papéis de Aspern: anotações para um debate. In: KOFFES, Suely (org.). Histórias de vida, Biografias e trajetórias. Unicamp: Cadernos IFCH, n. 31, 2004, pp. 5-16. KOPPER, Moisés. Arquiteturas da esperança: uma etnografia da mobilidade econômica no Brasil contemporâneo. Tese (doutorado em Antropologia Social), Instituto de Filosofia e Ciências Humanas, Universidade Federal do Rio Grande do Sul, 2016.

Da 'Nova Classe Média' ao Mercado da Casa Própria: Etnografia dos processos de mobilidade social e espacial no Brasil Contemporâneo. Anais X RAM, Córdoba - Argentina, 2013.

KOWARICK, Lúcio. Viver em risco - sobre a vulnerabilidade socioeconômica e civil. São Paulo, Editora 34, 2009.

LEPETIT, Bernard. Por uma nova história urbana. São Paulo, Edusp, 2001.

LINDÓN, Alicia. Espacialidades, desplazamientos y trasnacionalismo. Papeles de Población, v. 13, n. 53, 2007, pp. 71-101.

. El mito de la casa propia y las formas de habitar. Scripta Nova, Revista Electrónica de Geografía y Ciencias Sociales, v. IX, n. 194, 2005.

MACHADO DA SILVA, Luiz Antonio; LEITE, Márcia Pereira. Violência, crime e polícia: o que os favelados dizem quando falam desses temas? Sociedade e Estado, v. 22, n. 3, Brasília, set./dez. 2007, pp. 545-591.

MALLART, Fábio. Cadeias dominadas: Dinâmicas de uma instituição em trajetórias de jovens internos. Dissertação (mestrado em antropologia social), Universidade de São Paulo, 2011.

MARCELIN, Louis Herns. A linguagem da casa entre os negros no recôncavo baiano. Mana, v. 5, n. 2, 1999, pp. 31-60.

NERI, Marcelo. A Nova Classe Média: o lado brilhante dos pobres. Rio de Janeiro, CPS/ FGV, 2008.

POCHMANN, Marcio. Nova Classe Média? O trabalho na base da pirâmide social brasileira. São Paulo, Boitempo, 2012.

REVEL, Jacques (org.). Jogos de Escalas. A experiência da microanálise. Rio de Janeiro, Editora Fundação Getúlio Vargas, 1998.

RIZEK, Cibele Saliba. Cotidiano, cidade e experiência. Questões e apontamentos de pesquisa. Anais XIII Seminário de História da Cidade e do Urbanismo, Brasília, 2014.

ROCHA, Lia. Uma favela diferente das outras? Rotina, silenciamento e ação coletiva na favela do Pereirão, Rio de Janeiro. Tese (Doutorado em Sociologia), Instituto de Pesquisas do Rio de Janeiro, 2009.

ROLNIK, Suely. Cartografia Sentimental. Transformações contemporâneas do desejo. São Paulo, Editora Estação Liberdade, 1989.

ROSA, Thaís Troncon. Cidades Outras: pobreza, moradia e mediações em trajetórias urbanas liminares. Tese (Doutorado em Arquitetura e Urbanismo), IAU - USP, São Carlos, 2014. 
Da casa própria à casa manjada: dinâmicas socioespaciais e vulnerabilidades territorializadas nas periferias urbanas. In: $39^{\circ}$ Encontro Anual da ANPOCS, 2015, Caxambu. $39^{\circ}$ Encontro Anual da ANPOCS, 2015.

SANTO AMORE, Caio; SHIMBO, Lúcia Zanin; RUFINO, Maria Beatriz Cruz. Minha casa... E a cidade? Avaliação do programa minha casa minha vida em seis estados brasileiros. Rio de Janeiro, Letra Capital, 2015.

SEGURA, Ramiro. Paisajes del miedo en la ciudad. Miedo y ciudadanía en el espacio urbano de la ciudad de La Plata. Cuaderno Urbano. Espacio, Cultura, Sociedade, v. 8, n. 8, 2009, pp. 59-91.

SMITH, Neil. Geografía, diferencia y las políticas de escala. Terra Livre. São Paulo, v. 18, n. 19, 2002, pp. 127-146.

SOUZA, Jessé. Os Batalhadores Brasileiros. Nova classe média ou nova classe trabalhadora? Belo Horizonte, Editora UFMG, 2010.

TELLES, Vera da Silva. Prospectando a cidade a partir de suas margens: notas inconclusas sobre uma experiência etnográfica. Contemporânea - Revista de Sociologia da UFSCar. São Carlos, v. 3, n. 2, 2013, pp. 359-373.

. Debates: a cidade como questão. ; CABANES, Robert. (orgs). Nas tramas da cidade: trajetórias urbanas e seus territórios. São Paulo, Humanitas, 2006.

. Trajetórias urbanas: fios de uma descrição da cidade. In: ; CABANES, Robert. (orgs). Nas tramas da cidade: trajetórias urbanas e seus territórios. São Paulo, Humanitas, 2006a.

VELHO, Gilberto. Projeto e Metamorfose: antropologia das sociedades complexas. Rio de Janeiro, Jorge Zahar Editor, 1994.

Recebido em: 18/07/2019

Aprovado em: 06/12/2019

\section{Como citar este artigo:}

ROSA, Thaís Troncon. O fazer-cidade entre deslocamentos e vizinhanças: reflexões baseadas nas trajetórias urbanas de mulheres em busca de moradia no estado de São Paulo. Contemporânea - Revista de Sociologia da UFSCar, v. 9, n. 3, set.- dez. 2019, pp. 723.744 . 